\title{
EL COVID-19 Y LA CRISIS CARCELARIA EN TIEMPOS DE PANDEMIA: UNA PERSPECTIVA DESDE EL PANORAMA PENITENCIARIO EN BRASIL
}

\author{
COVID-19 AND THE PRISON CRISIS IN TIMES OF PANDEMIC: A \\ PERSPECTIVE FROM THE BRAZILIAN PENITENTIARY SYSTEM OVERVIEW
}

\author{
Stephanie Carolyn Perez
}

\begin{abstract}
Resumen: Siendo un absoluto honor publicar entre un medio de librepensadores, resulta apropiado este espacio para discutir las graves problemáticas que vive la población carcelaria en América del Sur, haciendo una mirada en especial cuanto al panorama penitenciario en Brasil, teniendo en cuenta la pandemia COVID-19 y su diseminación en este país. El trabajo se desarrolla haciendo uso de un método analítico-descriptivo, tomando como fuentes directas de normatividad y dogmática vigentes, mediante una exposición del panorama penitenciario en Brasil. El argumento se construye teniendo en cuenta que la humanidad ha venido enfrentando una prueba sin precedentes con la proliferación de la pandemia del COVID-19. La gravedad del virus es extrema, y ello se ha visto reflejado en amplio alcance de su propagación por todas partes del mundo. Para el caso concreto de Brasil, la pandemia ha causado miles de contagios y muertes y fue necesario poner en marcha acciones para detener el contagio, especialmente dentro de las cárceles, donde están concentradas las mayores condiciones de vulnerabilidad y por eso, las poblaciones que se encuentran privadas de libertad son quienes necesitan de una atención mayor por parte del Estado. Se concluye que resulta importante un control eficaz de la infección en el medio penitenciario, por medio de una coordinación estrecha entre los sectores de la salud, los servicios sanitarios de los centros penitenciarios y el Poder Judiciario para hacer frente a este estado de pandemia que enfrentamos en los días de hoy.
\end{abstract}

Palabras Claves: Sistema Carcelario. Crisis Carcelaria. Vulnerabilidad. COVID-19.

Abstract: Being an absolute honor to publish in this freethinkers space, is appropriate to discuss the serious problems that the prison population in South America is experiencing, taking a special look at the prison scene in Brazil, taking into consideration the COVID-19 pandemic and its dissemination in this country. The article is developed using an analytical-descriptive method, taking as direct sources regulations and dogmatics, through an exposition of the prison scene in Brazil. The argument is built taking into account that humanity has been facing an unprecedented test with the proliferation of the COVID-19 pandemic. The severity of the virus is extreme, and this has been reflected in the wide scope of its spread throughout the world. In the specific case of Brazil, the pandemic has caused thousands of infections and deaths and it was necessary to implement actions to

\footnotetext{
* Abogada. Profesora de Derecho Penal, Derecho Procesal Penal y Ejecución Penal en los cursos de grado y posgrado. Estudiante del Programa de Doctorado en el Área del Derecho Penal, Universidad de Buenos Aires - Argentina. Licenciada y Magíster en Derecho, Pontificia Universidade Católica de São Paulo - Brasil. E-mail: stephanie_carolyn@hotmail.com
} 
stop the contagion, especially inside prisons, where the greatest conditions of vulnerability are concentrated and therefore, that population who are deprived of liberty need more attention from the State. It is concluded that effective control of infection in the prison environment is important, through close coordination between the health sectors, the health services of the prison centers and the Judiciary to face this state of pandemic that we face in the present day.

Keywords: Prison System. Prison Crisis. Vulnerability. COVID-19.

Recebido em: 23/09/2020. Aceito em: 13/10/2020. 


\section{INTRODUCCIÓN}

La situación del COVID-19 es de interés mundial y el abordaje desde el panorama penitenciario es de interés jurídico. El presente artículo pretende informar sobre el riesgo que actualmente corren las poblaciones privadas de libertad frente a la propagación del COVID-19 en los establecimientos penales. La humanidad enfrenta una prueba sin precedentes con la proliferación de la pandemia del COVID19. La gravedad del virus es extrema, y ello se ha visto reflejado en lo amplio del alcance de su propagación por todas partes del mundo, especialmente en América del Sur. Para el caso concreto de Brasil, la pandemia ha causado miles de contagios y muertes.

El trabajo realiza una descripción del sistema penitenciario en Brasil, destacando problemas tales como el hacinamiento, la falta de higiene y de condiciones de vida digna. Esta situación es sin dudas alarmante y se repite en muchos países de Latinoamérica. El tema elegido es de gran utilidad para pensar y reflexionar sobre los problemas y posibles soluciones que se pueden presentar en torno a esta problemática y en relación a los países de la región. Asimismo, el trabajo se relaciona con el COVID-19, situación que agrava la problemática del sistema penitenciario y hace que los Estados se vean obligados a brindar una solución de manera rápida.

En efecto, los países alrededor del mundo tuvieron que poner en marcha acciones para detener el contagio y la propagación del virus, especialmente dentro de las cárceles, donde están concentradas las mayores condiciones de vulnerabilidad y por eso, las poblaciones que se encuentran privadas de libertad son quienes necesitan de una atención mayor por parte del Estado, por las razones que se verán a continuación.

\section{SISTEMA PENITENCIARIO Y COVID-19: UNA PERSPECTIVA DESDE BRASIL}

\subsection{Antecedentes}


La cuestión sobre la crisis carcelaria es un problema que siempre existió y que se ha agudizado con la pandemia del COVID-19. Es un problema grave y la pandemia ayudó a dar visibilidad a este gran colapso carcelario que afronta y viola los derechos humanos.

El principal problema suele ser el de la sobrepoblación penitenciaria, que representa un grande obstáculo para el propósito resocializador de los centros penitenciarios. Sobre el tema, Zysman Quirós (2012, p. 140) señala que: "uno de los principales problemas de los sistemas penales contemporáneos, como hemos visto, es la gestión de una creciente población penitenciaria en todo el globo. Probablemente, ello no hubiera sido imaginable doscientos años antes".

A su turno, Rivera Beiras (2009, p. 140):

La caída del mito de la resocialización "a través de" la cárcel, constituye hoy un dato incuestionable. Junto a ello, la imposibilidad de contener el aumento de la población penitenciaria (en algunos países de los mencionados, durante el tiempo indicado, el incremento de presencias penitenciarias se multiplicó por tres y cuatro veces), terminó por dibujar un panorama sombrío. Los aludidos países presentan el la actualidad sistemas penitenciarios colapsados, ineficaces para el cumplimiento de sus pretendidas funciones, con elevadísimos porcentajes de presos enfermos, altísimos índices de extranjeros encarcelados y con clientelas penitenciarias que siguen reclutándose de los estratos sociales más desfavorecidos. (RIVERA BEIRAS, 2009, p. 140).

La situación de las cárceles en Brasil - y en los países de América del Sur también - ya se hacía insostenible desde mucho tiempo. Son precarias condiciones de los centros penitenciarios asociadas a la deshumanización de las personas que están custodiadas, ausencia de infraestructura física e institucional, sobrepoblación carcelaria, entre otros asuntos que lamentablemente expresan la ineficacia del Estado para hacerle frente a un tratamiento digno a las personas que hacen parte del sistema carcelario, haciendo de los centros penitenciarios un espacio tortuoso no solo para los que están presos sino también para sus familiares y para los trabajadores del sistema. No podemos olvidarnos de que las cárceles fueron pensadas para servir a la seguridad de los presos. No fueron pensadas para ser lugares para castigo y deshumanización ${ }^{1}$.

\footnotetext{
${ }^{1}$ En este sentido: "Las Cárceles serán sanas y limpias, para seguridad y no para castigo de los reos detenidos en ellas, y toda medida que con el pretexto de precaución conduzca a mortificarlos, más allá de lo que aquella exija, hará responsable al juez que la autorice" (ARGENTINA, [1995]).
} 
Se pregunta: ¿Por qué hay personas presas? Lo que se espera como respuesta es: porque son culpables. Claro que así debería ser. Pero no es. La verdad es que más de la mitad de los presos no son culpables. Y no son culpables no porque sean todos inocentes o porque hayan sido detenidos injustamente, sino porque para que sean culpables es necesario existir una sentencia firme que haya sido revisada por todas las instancias judiciales para decir que alguien es culpable. En cuanto no exista esta sentencia firme la persona es inocente ante la ley y principalmente ante el Estado de Derecho.

Los que están custodiados en su mayoría son presos que no tienen una condena en firme o ni siquiera tienen una condena. Sea o no culpable, tenga o no una sentencia firme, una cosa se debe decir desde luego: un preso es un ser humano, no importa cual fue el injusto practicado. Es y siempre será un ser humano. El delincuente no es un enemigo, es un ciudadano.

Sobre los presos que no tienen todavía una condena para que se pueda decir que son culpables, así señala el jurista Zaffaroni (2017, p. 14):

\footnotetext{
La pena más grave es la privación de libertad (prisión), que se aplica incluso anticipadamente, como prisión preventiva, es decir, para evitar que el procesado se fugue y no se lo pueda condenar, o sea, se le hace sufrir la pena para que no la eluda si se llega a imponer en la sentencia. La mayoría de los presos, por ende, no son condenados, sino que están presos por las dudas. Y la prisión es una institución que deteriora, porque sumerge en condiciones de vida especialmente violentas, totalmente diferentes de las de la sociedad libre [...]. (ZAFFARONI, 2017, p. 14, grifo nosso).
}

Específicamente para el caso de Brasil, de acuerdo con el Consejo Nacional de Justicia (CNJ), en 2019 un total de 2,4 millones nuevas causas penales ingresaron al Poder Judicial Brasileño, de las cuales 1,6 millones (58,5\%) estaban en la etapa sumaria; 18,1 mil $(0,6 \%)$ en etapa recursal en los tribunales que juzgan los delitos menos graves (aquellos con penas que no superan los 2 años con o sin multa acumulada); 628,4 mil (22,4\%) en etapa recursal de apelaciones y 121,4 mil (4,3\%) en los Tribunales Superiores (el Superior Tribunal de Justicia o el Supremo Tribunal Federal). Además de estos casos, se iniciaron el cumplimiento de 395,5 mil $(14,1 \%)$ ejecuciones penales en primer grado. Resulta importante decir como se da el proceso penal en Brasil. En manera sucinta, tenemos 2 instancias judiciales, a las cuales se nombra "justicia de $1^{0}$ grado" y "justicia de 20 grado". Mientras se 
investiga y se dicta una sentencia condenatoria o absolutoria el proceso tramita en la justicia de $1^{\circ}$ grado. Si el imputado recurre del fallo entonces el proceso empieza su tramitación recursal en la justicia de $2^{\circ}$ grado. Por su parte, en el $2^{\circ}$ grado tenemos una primera instancia que juzga los recursos de apelación y una segunda instancia que juzga los recursos de casación. Por fin, la competencia penal en Brasil se ejerce por jueces y tribunales que la Constitución Federal de la Republica Federativa de Brasil y la ley instituyan, así que hay una justicia de los Estados brasileños con atribuciones para juzgar casos de competencia estadual y una justicia federal, con atribuciones para juzgar casos de competencia federal.

"La Justicia del Estado es por cierto el segmento con mayor representación de litigios en el Poder Judicial, con el 68,4\% de la demanda. En el ámbito penal, esta representatividad aumenta al 91,4\%". (CONSELHO NACIONAL DE JUSTIÇA, 2020a, p. 192, tradução nossa).

En la gráfica abajo se nota la evolución a lo largo de los años del crecimiento de las nuevas causas judiciales criminales en $1^{\circ}$ y $2^{\circ}$ grado y en los Tribunales Superiores, excluidas las ejecuciones penales.

Gráfica 1 - Estadísticas de las nuevas causas judiciales criminales en $1^{\circ}$ y $2^{\circ}$ grado y en los Tribunales Superiores excluidas las ejecuciones penales

Figura 141: Série hístórica dos casos novos e pendentes criminais no $1^{\circ} \mathrm{grau}$, no $2^{\circ} \mathrm{grau}$ e nos tribunais superiores, excluidas as execuçōes penais

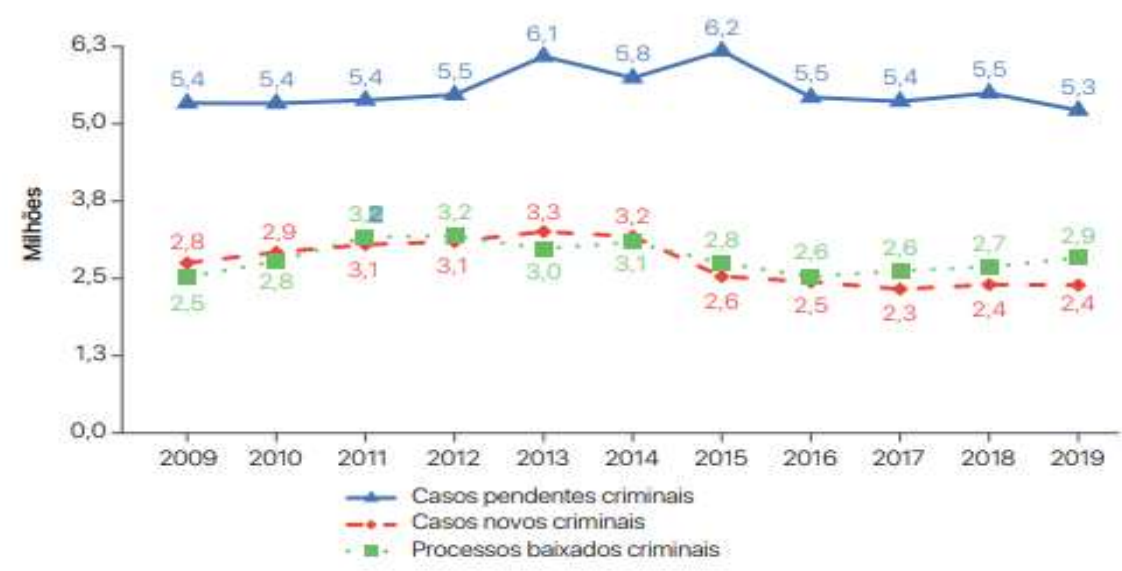

Fonte: Conselho Nacional de Justiça, 2020a, p. 192.

Sabemos que los actuales sistemas penales se basan en postulados progresistas y humanitarios acerca del fenómeno punitivo. Es decir: a pesar de la 
existencia de la pena y de la necesidad de que el Estado castiga al imputado por el hecho, la pena siempre debe imponerse sobre la base de los derechos y garantías fundamentales del ser humano, evitando así la existencia -y consecuentemente la aplicación -de penas crueles, inhumanas o que de alguna forma no respeten el postulado de la dignidad de la persona humana.

No podemos olvidarnos de que hay personas que están detenidas en lugares que ni siquiera fueron creados para ser prisiones, como por ejemplo las comisarías, que además de no tener infraestructura para custodiar presos no tienen funcionarios con formaciones específicas del sistema penitenciario. Las comisarías son lugares sin espacio para que los presos salgan a caminar, sin espacio para que vean la luz del sol, que no garantizan la exposición diaria de los custodiados al aire libre para que puedan practicar actividades para mantener la salud física y bienestar psicosocial, sin adecuadas condiciones de higiene y que deshumanizan los derechos humanos.

Las comisarías fueron creadas para tener gente de manera transitoria y no de manera permanente como suele suceder. Las comisarías fueron creadas para que, si una persona sea detenida, pase ahí una noche y al día siguiente sea presentada a la autoridad judicial y no para quedarse ahí eternamente detenida.

Hechas estas consideraciones preliminares, hablemos ahora sobre la situación de las cárceles en Brasil que es por cierto una de las más preocupantes en América del Sur. Las cárceles brasileñas son lugares donde no hay justicia y sobre todo no hay humanidad.

Para tener una idea de la situación actual en Brasil, es preciso seguir algunos datos obtenidos en el "Levantamento Nacional de Informações Penitenciárias Dezembro de 2019", del Departamento Penitenciário Nacional (DEPEN): Brasil tiene una población, contabilizada hasta diciembre de 2019, de 748.009 mil presos, entre los cuales 362.547 mil están detenidos en el régimen cerrado, 133.408 mil en el régimen semiabierto, 25.137 mil en el régimen abierto y 222.558 mil son presos provisorios, es decir, sin condena en firme (la gran mayoría ni siquiera habían sido condenados $^{2}$ ). (DEPARTAMENTO PENITENCIÁRIO NACIONAL, 2019, p. 2).

\footnotetext{
${ }^{2}$ De acuerdo con el Consejo Nacional de Justicia, los casos pendientes, o sea, sin sentencia, equivalen a 2,5 veces la demanda existente en el Poder Judiciario Brasileño. (CONSELHO NACIONAL DE JUSTIÇA, 2020a, p. 192).
} 
Gráfica 2 - Población carcelaria en Brasil - Sistema de Informaciones Estadísticas del Sistema Carcelário Brasileño

\section{Presos em unidades prisionais no Brasil}

Periodo de julho a dezembro de 2019

$$
\text { de julho a dezembro cie }
$$
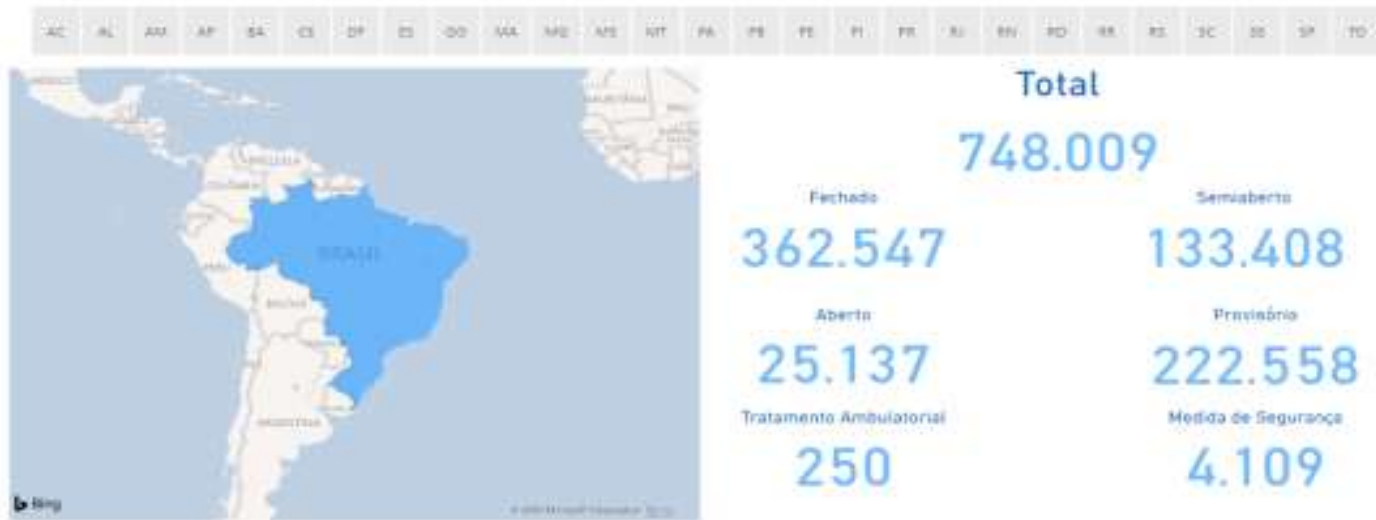

Fonte: Departamento Penitenciário Nacional, 2019, p. 2.

En Brasil, entrar en una cárcel significa perder los derechos humanos, perder los derechos para una vida digna. Los establecimientos carcelarios en Brasil son lugares donde no son respetadas las mínimas garantías de la dignidad humana.

No hay atención sanitaria a los reclusos, no hay acceso rápido a la atención médica para casos urgentes, no hay limpieza de los lugares de alojamiento. La comida no tiene calidad. No hay lavamanos para todos, no hay agua potable, no hay condiciones mínimas de higiene. No hay fumigaciones, desratizaciones ni tampoco desinfecciones de los alojamientos. El Estado no ofrece a los presos elementos básicos y esenciales para la higiene. Los locales de alojamiento de los reclusos no cumplen con normas de higiene, particularmente con respecto a existencia de ventanas para que haya circulación de aire y para que haya luz natural. Hay hacinamiento y los presos no caben en las celdas. Hay presos que duermen todos los días en los pasillos, otros en el baño y otros que comparten cama. Dicha sobrepoblación de presos repercute también en la calidad de vida de los presos, afectando el acceso a la salud y a la higiene. En este sentido, De La Fuente (2019, p. 279):

La sobrepoblación no sólo repercute en la cantidad de metros destinada a cada ser humano que es detenido, sino también que lo hace de manera 
negativa en la calidad de vida (se afecta el acceso a la salud, a la educación, a la higiene, etc.)

Es así que alojar más personas no suele traer aparejada la construcción de nuevas aulas, contratar más profesionales de la salud, aumentar la provisión de elementos de limpieza y higiene. De este modo llegamos a ver afectada la higiene personal de los/las internos/as. (DE LA FUENTE, 2019, p. 279).

Estos son solamente algunos de los variados ejemplos de situaciones de flagrante irrespeto a los derechos de los presos. Las cárceles no solo no cumplen su objetivo resocializador, no garantizan la seguridad y la salud de los presos, sino que además deshumanizan los presos y los hacen vulnerables a las condiciones inhumanas de sostenimiento de la vida en estos espacios.

La imagen se repite en toda América Latina, donde el hacinamiento carcelario alcanza el 60\%, según el Instituto para la Investigación de Política Criminal (ICPR, por sus siglas en inglés), un centro de estudios con base en Londres. Es decir: si hay espacio para 100 personas, en él viven un promedio de 160. (PARDO, 2020).

La BBC News asi notició en 5 de mayo de 2020 la situación en países de Latinoamérica:

(...) El nerviosismo se propaga por las cárceles de toda la región. En Lima, Perú, un motín por temor al contagio de coronavirus dejó 9 muertos y más de 60 heridos; en otro incidente similar en Guanare, Venezuela, perdieron la vida más de 40 personas.

En Sao Paulo, Brasil, 1.200 reclusos escaparon de varias cárceles en medio de motines. En Argentina, 1.200 presos están en huelga de hambre para protesta por condiciones "infrahumanas".

Y en El Salvador, país con una de las mayores tasas de hacinamiento de la región, el gobierno de Nayib Bukele juntó a todos pandilleros presos de grupos rivales en pequeños espacios y divulgó unas polémicas fotos que dieron la vuelta al mundo.

Prácticamente todas las cárceles latinoamericanas sufren hacinamiento. Es lo contrario a lo que se necesita para frenar la propagación del coronavirus: el aislamiento social.

(...)

La fuga masiva en Brasil se dio cuando el gobierno prohibió la salida de 34.000 prisioneros que tenían beneficios de libertad condicional. Las imágenes de los prófugos corriendo por las calles de la Sao Paulo dieron la vuelta al mundo. (PARDO, 2020).

Fue en estas cárceles que vino la pandemia del COVID-19. En estos lugares con sobrepoblación, donde los presos viven hacinados y sin los mínimos cuidados de higiene y limpieza se instaló el coronavirus.

Rivera Beiras (2019, p. 479) bien señala que: 
También debe ser afrontada la dramática situación que, en relación con las problemáticas sanitarias y de salud de los encarcelados, presentan la totalidad de los sistemas penitenciarios del presente.

(...) Numerosas investigaciones demuestran, en la actualidad, no sólo el surgimiento de nuevas patologías - que hallan su etiología en la permanencia prolongada de individuos en las penitenciarías-, sino también el extraordinario factor patógeno que la cárcel supone para individuos aquejados de enfermedades infecto-contagiosas, asociadas o no a las denominadas "enfermedades oportunistas" derivadas de la infección del HIV-SIDA. (RIVERA BEIRAS, 2019, p. 479).

En estos lugares donde no hay higiene constante y donde no hay condiciones suficientes de salud se instaló un virus con enorme poder letal. Se trata de una cuestión grave porque la población carcelaria es vulnerable dadas las condiciones de precarización a las que están sometidos los reclusos.

Connectas, una iniciativa periodística sin fines de lucro que promueve la producción, el intercambio, la capacitación y la difusión de información sobre temas claves para el desarrollo de las Américas, así informó sobre la situación en las cárceles de Latinoamérica:

(..) Al menos 47 muertos y 75 heridos. Según el Observatorio Venezolano de Prisiones, esa fue la cifra que resultó de un motín en la prisión de Guanare, en el centro de Venezuela, luego de que restringieran las visitas como medida de cordón sanitario para evitar la propagación del coronavirus.

(...)

Adicional a esta propuesta, a finales de abril, un centenar de presos se subieron a los techos de la cárcel de Devoto, en Buenos Aires, a fin de reclamar por el hacinamiento que para entonces se vivía. Si bien el sistema ya cuenta con 119 plazas disponibles para el ingreso de otras personas, la situación en las cárceles argentinas no ha mejorado; todavía hay déficit de atención médica, de alimentación y de alojamiento, según los reclamos de los detenidos.

En el caso de Perú, los presos denunciaron estar abandonados ante la enfermedad, por lo que se amotinaron y exigieron atención médica. Las protestas estallaron en el penal Miguel Castro, en Lima, extendiéndose poco después a otras cinco cárceles, tres en la capital y dos en el interior del país, dejando un saldo de nueve reclusos muertos. "Queremos las pruebas de covid-19", "Tenemos derecho", Nos estamos muriendo, ayúdennos" y "Medicinas y libertad" son algunos de los mensajes que se leen en los carteles que ondean desde las cárceles.

(...)

En Colombia, el Gobierno de Iván Duque decretó a finales de marzo la emergencia carcelaria, luego de que un motín en la Cárcel Modelo de Bogotá dejara 23 muertos y al menos 90 heridos. En este centro penitenciario se han detectado más de 70 casos confirmados por covid-19, y tres de ellos han fallecido. Los hechos aún son investigados por las autoridades competentes.

La situación de contagio es aún más grave en la cárcel de Villavicencio, donde se contabilizan más de 800 casos, lo que representa el 87 por ciento de los contagios en cárceles de Colombia, según cifras de El Espectador. 
Miguel Ángel Rodríguez, director de ese centro penitenciario, reveló que no es posible garantizar un aislamiento en el penal si hay "gente durmiendo debajo de las camas y en los baños". (LUCERO, [2020]).

Los presos, aún estando presos también pueden y van a enfermarse. $Y$ cuando se enfermen van a utilizar los mismos recursos de salud que las personas que no están presas generando un colapso en el sistema de salud.

Los estudios indican que las cárceles pueden convertirse en verdaderas incubadoras de enfermedades. Los datos de febrero de este año de 2020 apuntan al menos 500 casos del virus en las cárceles chinas, además de una ola de despidos de funcionarios penitenciarios debido a la falta de medidas preventivas y de control.

Además del hacinamiento y la notoria deficiencia en los mecanismos de ventilación y salud de las cárceles, la propia rutina carcelaria conduce a la proliferación de enfermedades y al empeoramiento generalizado de la situación de las víctimas. El bajo contenido nutricional de la dieta, el sedentarismo, el posible uso de drogas y la fragilidad emocional inherente a la condición de preso conforman un cóctel de condiciones perfectas para ello.

Para evitar la propagación de enfermedades como el COVID-19 son fundamentales condiciones ambientales e higiénicas de los establecimientos carcelarios. En este sentido, De La Fuene (2019, p. 277):

A los fines de preservar la salud, evitar la propagación de enfermedades como así también para ayudar en la recuperación de la salud, resulta importante la limpieza de los lugares de alojamiento, así como las condiciones del medio ambiente en donde se encuentra emplazado el centro penitenciario.

Es deber de la administración penitenciaria realizar fumigaciones, desratizaciones, desinfecciones, estudios del agua que se suministra a la población alojada ( $\mathrm{y}$ a los y las agentes que trabajan), cerciorarse que no haya fuentes de contaminación en la zona. (DE LA FUENTE, 2019, p. 277).

El COVID-19 puede ser el detonante de una nueva mentalidad sobre el sistema y la necesidad de ampliar las políticas de salud pública que, más allá de las rejas y los muros, las cárceles no son un mundo aparte de la sociedad.

Por eso, organismos internacionales como la Organización Mundial de la Salud (OMS) y la Comisión Interamericana de Derechos Humanos (CIDH) emitieron recomendaciones para evitar el ingreso del COVID-19 a las cárceles, su reproducción y esparcimiento, para evitar una catástrofe porque se comprende que los lugares de 
detención, en particular aquellos donde existe sobrepoblación podrían ser espacios proclives a una rápida propagación del virus.

La Oficina del Alto Comisionado de la ONU para los Derechos Humanos, aseguró que en "muchos países, los centros de detención están sobrepoblados, y en algunos casos, en peligro de estarlo, por lo que la distancia social y el aislamiento en estas condiciones son prácticamente imposibles". Ante esta situación, hizo un llamado a los gobiernos de la región para tomar "acciones urgentes para proteger la salud de las personas detenidas".

La Oficina de Naciones Unidas contra la Droga y el Delito (UNODC), la Organización Mundial de la Salud (OMS), el Programa Conjunto de las Naciones Unidas sobre el VIH/Sida (ONUSIDA) y la Oficina del Alto Comisionado para los Derechos Humanos (ACNUDH) emitieron una declaración conjunta sobre el COVID19 en prisiones y otros centros de detención, que así decía:

Habida cuenta del hacinamiento que se produce en muchos centros de detención, algo que pone en peligro la higiene, la salud, la seguridad y la dignidad humana, queda claro que no basta con aplicar una respuesta sanitaria para la COVID-19 en esos entornos. El hacinamiento supone un obstáculo infranqueable a la prevención, preparación y respuesta ante esta enfermedad.

Exhortamos a los líderes políticos a que estudien la posibilidad de limitar la privación de libertad, por ejemplo la prisión preventiva, a una medida de último recurso, en particular en caso de hacinamiento en los centros, y a buscar soluciones en las que se evite la reclusión. Entre esas medidas debería figurar la posibilidad de poner en libertad a reclusos con un riesgo particular de COVID-19, como personas mayores y personas con afecciones preexistentes, así como a reclusos que no suponen un riesgo para la seguridad pública, como aquellos condenados por delitos menores y no violentos, en particular mujeres y niños.

Para reducir el riesgo de que se produzcan brotes de COVID-19 en centros penitenciarios y otros lugares de reclusión, es fundamental aplicar una respuesta rápida y firme destinada a asegurar que las condiciones de detención son saludables y seguras y que se reduce el hacinamiento. Aumentar la limpieza y la higiene en esos lugares es primordial para prevenir la entrada del virus o limitar su propagación.

Deberían cerrarse los centros de detención y rehabilitación obligatoria en los que se detiene a personas sospechosas de consumir drogas o de delitos de prostitución sin haber sido juzgados debidamente, con el pretexto de un posible tratamiento o rehabilitación. No hay pruebas de que ese tipo de centros sean eficaces en el tratamiento o rehabilitación de toxicómanos y su detención plantea problemas de derechos humanos y pone en peligro la salud de los detenidos, lo que incrementa el riesgo de que se produzcan brotes de COVID-19. (OMS, 2020). 
Según la guía publicada el 15 de marzo de 2020 por la $\mathrm{OMS}^{3}$, el esfuerzo global para abordar la propagación de la enfermedad puede fallar sin la atención adecuada a las medidas de control de infecciones dentro de las cárceles.

Siguiendo dichas recomendaciones, los países empezaron entonces a adoptar medidas de excarcelación de los presos, como ocurrió en Francia, EEUU, Argentina, Italia y claro, en Brasil.

Estas medidas no fueron adoptadas por clemencia o piedad a los presos, tampoco como conmutación de la pena, sino para bajar los factores de riesgo de contagio y contaminación, y así proteger la salud de cada uno de nosotros, es decir: proteger la salud de los presos y de los que no estén presos.

A continuación, hablaremos sobre las medidas adoptadas por el Sistema Judiciario Brasileño para combatir la propagación del COVID-19 en las cárceles brasileñas.

\subsection{Medidas adoptadas en Brasil para la contención del COVID-19}

El brote del COVID-19 se detectó por primera vez en Wuhan, China y rápidamente fue avanzando por todo el mundo. En 11.03.2020, la OMS clasificó el nuevo coronavirus como una pandemia, o sea, una enfermedad epidémica que se extiende en varios países del mundo de manera simultánea.

El primer caso confirmado del COVID-19 en Brasil ocurrió en 26.02.2020. Fue un hombre de 61 años que viajó a Italia. Pocos días después, en 29.02.2020, fue confirmado el segundo caso. El paciente fue un hombre de 32 años que llegó de la región de la Lombardía, en Italia. El 04.03.2020, fue confirmado el tercero caso: un hombre que viajó a Europa. El 05.03.2020, el país ya tenía 8 casos confirmados y en 17.03.2020, se confirmó la primera muerte en Brasil que ocurrió en la Ciudad de San Pablo.

\footnotetext{
3 La OMS publicó en 15.03.2020, una guía para abordar el tema del COVID-19 en las cárceles instando a los gobiernos a crear un sistema de coordinación entre los sectores de la Sanidad y la Justicia, junto al personal penitenciario, para luchar contra el virus y su impacto en la población carcelaria. La guía, denominada "Preparación, prevención y control del COVID-19 en las cárceles y otros lugares de detención" proporciona información para el personal y los profesionales sanitarios que trabajan en las cárceles y las autoridades penitenciarias. (WORLD HEALTH ORGANIZATION, 2020). (disponible a la fecha solamente en inglés).
} 
Al principio se decía que eran más vulnerables a la contaminación y a una probable muerte los mayores de 60 años y personas que tenían enfermedades prexistentes. Por eso, en medio al avance del virus, en 18.03.2020, el ministro Marco Aurélio, del Supremo Tribunal Federal, recomendó que los jueces reevalúen con urgencia la situación de los presos que pertenecen al grupo de riesgo como mayores de 60 años, enfermos y embarazadas, para que fuera evaluada la posibilidad de que sean retirados del ambiente carcelario ante la gravedad de la situación del coronavirus en Brasil. Esta recomendación fue señalada en el fallo de la Tutela Provisória Incidental na Arguição de Descumprimento de Preceito Fundamental No 347, que así decía en su idioma original:

Ante a situação precária e desumana dos presídios e penitenciárias, no que levou o Colegiado Maior, na medida cautelar na arguição de descumprimento de preceito fundamental $n^{\circ} 347 / D F$, a concluir pelo estado de coisas inconstitucional, considerada a integridade física e moral dos custodiados, assento a conveniência e, até mesmo, a necessidade de o Plenário pronunciar-se.

De imediato, conclamo os Juízos da Execução a analisarem, ante a pandemia que chega ao País - infecção pelo vírus COVID19, conhecido, em geral, como coronavírus -, as providências sugeridas, contando com o necessário apoio dos Tribunais de Justiça e Regionais Federais. A par da cautela no tocante à população carcerária, tendo em conta a orientação do Ministério da Saúde de segregação por catorze dias, eis as medidas processuais a serem, com urgência maior, examinadas: a) liberdade condicional a encarcerados com idade igual ou superior a sessenta anos, nos termos do artigo $1^{\circ}$ da Lei $n^{\circ} 10.741$, de $1^{\circ}$ de outubro de 2003; b) regime domiciliar aos soropositivos para HIV, diabéticos, portadores de tuberculose, câncer, doenças respiratórias, cardíacas, imunodepressoras ou outras suscetíveis de agravamento a partir do contágio pelo COVID-19; c) regime domiciliar às gestantes e lactantes, na forma da Lei $n^{0} 13.257$, de 8 de março de 2016 - Estatuto da Primeira Infância; d) regime domiciliar a presos por crimes cometidos sem violência ou grave ameaça; e) substituição da prisão provisória por medida alternativa em razão de delitos praticados sem violência ou grave ameaça; f) medidas alternativas a presos em flagrante ante o cometimento de crimes sem violência ou grave ameaça; g) progressão de pena a quem, atendido o critério temporal, aguarda exame criminológico; e h) progressão antecipada de pena a submetidos ao regime semiaberto. (BRASIL, 2020, p. 9-10).

Se nota que frente a la propagación de la pandemia, los países empezaron a adoptar medidas de excarcelación de los presos porque el COVID-19 vino a dar visibilidad a las debilidades del sistema penitenciario. Fueron medidas de emergencia de desinstitucionalización en materia penitenciaria adoptadas como respuesta a la propagación del COVID-19 para reducir la población privada de libertad, en función 
de disminuir las consecuencias devastadoras que el virus podría tener en el ámbito penitenciario.

En muchos países de todo el mundo se han confirmado casos y muertes de COVID-19 entre presos y agentes carcelarios. La aparición y propagación de la pandemia en las cárceles ha provocado fugas, motines y protestas en varias cárceles de América del Sur.

Por ello, muchos gobiernos han tomado medidas para reducir la población carcelaria como estrategia clave para prevenir la pandemia.

Brasil ha sido uno de los países más afectados en América del Sur. En el inicio de la llegada del COVID-19 en Brasil el presidente brasileño ha tomado varias decisiones al respecto, como prohibir la salida bajo permiso de 34.000 prisioneros que ya estaban teniendo beneficios de libertad condicional, quienes tras disfrutar de esa autorización, deberían entonces regresar a las cárceles. La medida se justificó indicando que los detenidos tendrían un alto potencial de traer y propagar el coronavirus en una población vulnerable, de acuerdo con la Secretaría de Administración Penitenciaria ("SAP"). Esto llevó a que más de 1.000 presos se fugaran de prisiones de San Pablo, y tan solo unos 700 de ellos fueron capturados. Reclusos brasileños incluso grabaron videos amenazando con asesinar a los guardias a menos que el Gobierno actúe rápidamente para mejorar sus condiciones de detención.

En medio del aumento de casos y demostrando una fuerte preocupación con la población carcelaria, el Consejo Nacional de Justicia de Brasil (CNJ) dictó la Recomendación No 62, de 17 de marzo de 2020 direccionada a tribunales y magistrados para adopción de medidas preventivas a la propagación del COVID-19 en el sistema de justicia penal y socioeducativo (CONSELHO NACIONAL DE JUSTIÇA, 2020b). La Recomendación tiene por objetivo brindar a las autoridades judiciales competentes algunas recomendaciones prácticas para reducir el impacto de la pandemia COVID-19 en lugares de detención para proteger la salud y el bienestar de todos aquellos que viven, trabajan y visitan estos entornos y la población en general. Esa Recomendación tiene por objetivo también beneficiar a personas más vulnerables frente al coronavirus como los mayores de 60 años, madres gestantes y lactantes, personas con enfermedades crónicas graves, mientras también busca 
reducir el hacinamiento carcelario. Aunque sea una recomendación, se nota que los tribunales y magistrados están en su gran mayoría siguiendo lo que está postulado en dicha recomendación.

En un abordaje objetivo, la Recomendación establece que con relación a las personas que estén custodiadas, deben ser reevaluadas las prisiones provisorias, especialmente en cuanto a las personas que estén en los grupos más vulnerables, como madres, personas con discapacidad, mayores de 60 años o personas que estén presas en cárceles con sobrepoblación donde no haya atención médica. También se recomienda la reevaluación de la situación para personas presas a más de 90 días sin condena o de personas que estén presas por crímenes no graves, o sea, los que hayan sido cometidos sin violencia o sin grave amenaza a la víctima. En cuanto a los presos que ya estén cumpliendo condena, la Recomendación No 62 establece que los jueces evalúen la posibilidad de conceder de manera anticipada la libertad condicional o la salida anticipada para los casos previstos en ley o entonces dar arresto domiciliario a las personas que estén en el llamado grupo de riesgo. (CONSELHO NACIONAL DE JUSTIÇA, 2020b).

Otra recomendación es que el juzgador elija dar arresto domiciliario también a los presos que estén cumpliendo condena en régimen abierto o semiabierto ${ }^{4} \mathrm{o}$ cuando el preso presentar síntomas del COVID-19. Se nota que la Recomendación busca un flujo reducido de admisión a la prisión en Brasil.

También se recomienda la suspensión de realización de las audiencias de custodia, que la realización de audiencias urgentes sea por medio de videoconferencia (algo que no pasaba en Brasil donde las audiencias siempre se realizaron en manera presencial), y la adopción de medidas de salud pública en los espacios públicos, como disponibilidad de agua potable, jabón líquido, alcohol en gel, tapabocas y barbijos para reducir la contaminación.

\footnotetext{
${ }^{4}$ De acuerdo con el artículo 33 del Código Penal Brasileño, hay 3 régímenes de cumplimiento de la pena de reclusión: el cerrado, el semiabierto y el abierto. El régimen de cumplimiento es establecido de acuerdo con la condena. "Art. 33 - La pena de reclusión debe cumplirse en régímen cerrado, semiabierto o abierto. (...) Párrafo 20 - Las penas de reclusión se ejecutarán en manera progresiva, de acuerdo con el mérito del condenado, observando los siguientes criterios y sujeto a la posibilidad de traslado a un régimen más gravoso: a) el condenado con pena mayor a 8 (ocho) años debe comenzar a cumplirla en régímen cerrado; b) el condenado que no sea reincidente, condenado con pena mayor a 4 (cuatro) años y que no sea mayor que 8 (ocho) podrá, desde el inicio, cumplirla en régímen semiabierto; $c$ ) el condenado que no sea reincidente, con pena igual o menor a 4 (cuatro) años podrá, desde el inicio, cumplirla en régímen abierto." (BRASIL, [2019]).
} 
Así dicta la Recomendación, en su idioma original:

Art. 4o Recomendar aos magistrados com competência para a fase de conhecimento criminal que, com vistas à redução dos riscos epidemiológicos e em observância ao contexto local de disseminação do vírus, considerem as seguintes medidas:

I - a reavaliação das prisões provisórias, nos termos do art. 316, do Código de Processo Penal, priorizando-se: a) mulheres gestantes, lactantes, mães ou pessoas responsáveis por criança de até doze anos ou por pessoa com deficiência, assim como idosos, indígenas, pessoas com deficiência ou que se enquadrem no grupo de risco; b) pessoas presas em estabelecimentos penais que estejam com ocupação superior à capacidade, que não disponham de equipe de saúde lotada no estabelecimento, que estejam sob ordem de interdição, com medidas cautelares determinadas por órgão do sistema de jurisdição internacional, ou que disponham de instalações que favoreçam a propagação do novo coronavírus; c) prisões preventivas que tenham excedido o prazo de 90 (noventa) dias ou que estejam relacionadas a crimes praticados sem violência ou grave ameaça à pessoa;

$[\ldots]$

Art. 5o Recomendar aos magistrados com competência sobre a execução penal que, com vistas à redução dos riscos epidemiológicos e em observância ao contexto local de disseminação do vírus, considerem as seguintes medidas: I - concessão de saída antecipada dos regimes fechado e semiaberto, nos termos das diretrizes fixadas pela Súmula Vinculante no 56 do Supremo Tribunal Federal, sobretudo em relação às: a) mulheres gestantes, lactantes, mães ou pessoas responsáveis por criança de até 12 anos ou por pessoa com deficiência, assim como idosos, indígenas, pessoas com deficiência e demais pessoas presas que se enquadrem no grupo de risco; b) pessoas presas em estabelecimentos penais com ocupação superior à capacidade, que não disponham de equipe de saúde lotada no estabelecimento, sob ordem de interdição, com medidas cautelares determinadas por órgão de sistema de jurisdição internacional, ou que disponham de instalações que favoreçam a propagação do novo coronavírus; II - alinhamento do cronograma de saídas temporárias ao plano de contingência previsto no artigo $9^{\circ}$ da presente Recomendação, avaliando eventual necessidade de prorrogação do prazo de retorno ou adiamento do benefício, assegurado, no último caso, o reagendamento da saída temporária após o término do período de restrição sanitária; III concessão de prisão domiciliar em relação a todos as pessoas presas em cumprimento de pena em regime aberto e semiaberto, mediante condições a serem definidas pelo Juiz da execução; IV - colocação em prisão domiciliar de pessoa presa com diagnóstico suspeito ou confirmado de Covid-19, mediante relatório da equipe de saúde, na ausência de espaço de isolamento adequado no estabelecimento penal; $\mathrm{V}$ - suspensão temporária do dever de apresentação regular em juízo das pessoas em cumprimento de pena no regime aberto, prisão domiciliar, penas restritivas de direitos, suspensão da execução da pena (sursis) e livramento condicional, pelo prazo de noventa dias; [...]

Art. 70 Recomendar aos Tribunais e magistrados com competência penal que priorizem a redesignação de audiências em processos em que o réu esteja solto e a sua realização por videoconferência nas hipóteses em que a pessoa esteja privada de liberdade, com vistas à redução dos riscos epidemiológicos e em observância ao contexto local de disseminação do vírus. § $10 \mathrm{Na}$ hipótese de manutenção da realização de audiências, recomendase a adoção das seguintes medidas: I - restrição temporária da presença de visitantes do público em geral no recinto durante a solenidade; 
II - realização da audiência em espaços ampliados ou abertos, tais como salas destinadas aos plenários do júri e auditórios, permitindo maior distância respiratória entre as pessoas presentes; III - substituição temporária de magistrados e agentes públicos que pertençam ao grupo de risco; IV - adoção de medidas de higiene e de prevenção, tais como disponibilização de água corrente e sabão líquido, utilização de máscaras, álcool gel e outros produtos que possam reduzir o risco de contaminação e limpeza minuciosa das superfícies; V - garantia de salubridade e medidas de isolamento, quando necessário, na carceragem adjacente à sala de audiência; VI - uso excepcional de algemas, que devem ser higienizadas com material antiviral; VII - redução do tempo de permanência nas carceragens dos Fóruns. (CONSELHO NACIONAL DE JUSTIÇA, 2020b, p. 5-6, 6-7, 7-8).

De acuerdo con el Consejo Nacional de Justicia, entre marzo y mayo un total de 35.000 personas salieron de las unidades penitenciarias bajo la adaptación del tiempo de cumplimiento de pena a otros formatos, como el arresto domiciliario o el monitoreo electrónico. Esto representa el 4,6\% del total de personas privadas de libertad en las cárceles, excluido el régimen abierto y las personas que están encarceladas en comisarías. (CONSELHO NACIONAL DE JUSTIÇA, [2020]).

El Consejo Nacional de Justicia creó un sistema de monitoreo llamado "registros de contagio/muertos", un importante subsidio que desde el 15 de junio de 2020 acompaña los casos de contagio y muertes por Covid-19 en los sistemas penitenciario y socioeducativo en Brasil, categorizados entre servidores y personas privadas de libertad. (CONSELHO NACIONAL DE JUSTIÇA, [2020]).

Para que se tenga una idea del panorama en Brasil, en 15 de junio de 2020 cuando fue publicado el primero dato oficial, Brasil tenía 5.754 casos confirmados de COVID-19 entre los cuales 2.605 casos estaban entre los presos y 3.149 entre los trabajadores del sistema carcelario. Entre los presos, había 54 muertes confirmadas y entre los servidores, 41 muertes. (CONSELHO NACIONAL DE JUSTIÇA, [2020]).

El último reporte, publicado en 28 de septiembre de 2020 confirma 38.021 casos de COVID-19 entre los cuales 28.233 fueron confirmados entre los presos y 9.788 entre los trabajadores del sistema carcelario. Entre los presos, había 111 muertes confirmadas y entre los servidores, 84 muertes. (CONSELHO NACIONAL DE JUSTIÇA, [2020]).

No solo Brasil, sino que otros países alrededor del mundo están ahora enfrentando la necesidad de poner en marcha acciones en función de detener el contagio y de salvar vidas, especialmente cuanto a la población carcelaria que se 
caracteriza por su vulnerabilidad y que, por lo tanto, requiere una atención especial ya que padecen, con demasiada frecuencia, las consecuencias de problemas tales como el limitado acceso a salud, la sobrepoblación y el hacinamiento carcelarios.

Controlar la propagación de la infección en estos entornos es esencial para prevenir grandes brotes de COVID-19. Estas medidas son extremadamente importantes porque los presos, sean o no culpables, tengan o no condena firme, tienen que hacer el aislamiento. Y ¿cómo van a hacer el aislamiento en pabellones pensados para 10 personas y donde hay 150 personas? Es imposible el aislamiento en estas condiciones.

Es importante decir que los vulnerables no son apenas los presos, sino también las personas que trabajan en el sistema carcelario. Estas personas pasan el día en las cárceles y en las comisarías y al fin del día vuelven a sus casas, donde están sus familiares. Hay también los abogados que van a visitar sus clientes. Si estas personas se enferman, hay grande probabilidad de que transmitan el virus a sus familiares. Es por eso que tenemos que cuidar a todos que estén adentro del sistema carcelario: los presos y las personas que ahí trabajan todos los días.

Las medidas recomendadas por el Consejo Nacional de Justicia no son una amnistía, indulto o perdón del ofendido. No borran el delito y tampoco son una conmutación de la pena. Son medidas de emergencia adoptadas por un periodo transitorio. Nada más. Una vez todo vuelva a la normalidad, los presos van a volver a la cárcel y volverá entonces la discusión del problema de las cárceles tal cual existía antes de la pandemia.

En este contexto, las medidas recomendadas por el Consejo Nacional de Justicia por medio de la Recomendación No 62 (CONSELHO NACIONAL DE JUSTIÇA, 2020b), son medidas que desarrollan el respecto a los derechos humanos por medio de la adopción de medidas para combatir el hacinamiento carcelario y prevenir el riesgo de propagación del COVID-19, de manera a proteger las personas que se encuentran en una situación de mayor vulnerabilidad frente al COVID-19, combatiendo la sobrepoblación carcelaria, previniendo y mitigando el riesgo de propagación del virus.

Es decir: la implementación de las orientaciones dictadas por el Consejo Nacional de Justicia por medio de la Recomendación No 62 (CONSELHO NACIONAL 
DE JUSTIÇA, 2020b) está basada en las obligaciones estatales derivadas del derecho y de estándares internacionales en relación al respecto a los derechos humanos fundamentales como la dignidad humana, la vida, la integridad personal, la prohibición de la tortura y otros tratos o penas crueles, inhumanas o degradantes. El reto que los gobiernos enfrentan es por ende, velar por el cumplimiento de estos derechos a todos los seres humanos, principalmente a los que estén presos en este momento de emergencia causado por la pandemia.

Es necesario un control eficaz de la infección en el medio penitenciario, por medio de una coordinación estrecha entre los sectores de la salud, los servicios sanitarios de los centros penitenciarios y Poder Judiciario para abordar esta pandemia.

Este enfoque se construye a partir del vertiginoso escalamiento del brote, que trajo consecuencias catastróficas humanitarias sin precedentes, tan impredecibles como incalculables. El confinamiento bajo una sobrepoblación convierte a los establecimientos carcelarios en una zona de transmisión significativa del virus, poniendo en riesgo el estado de salud de las personas que interactúan en un medio asediado por el hacinamiento. En este contexto, surge para el Estado de Derecho, para las instituciones políticas y para los aparatos jurídicos el objetivo de garantizar los derechos subjetivos de los presos. Hay planteada una nueva agenda que se deriva directamente del hecho democrático.

Las coordenadas dentro de las cuales se reproduce el sistema carcelario son complejas, cargadas de tensiones y singulares. Se trata de tres dimensiones que se conjugan: democracia, pobreza y desigualdad. Estas dimensiones construyen democracias pobres y desiguales, donde los ciudadanos ejercen sus derechos con baja intensidad $y$, muchos de ellos, incluso se encuentran excluidos del ejercicio de derechos básicos.

La creación de un verdadero Estado de Derecho es también un proceso de creación y salvaguarda de la ciudadanía y de la democracia. Por lo que el Estado de Derecho y la democracia por medio de los gobiernos buscan, juntos, atender las sugerencias internacionales y adoptar medidas de contención para personas en condición de mayor vulnerabilidad, más que todo por el hacinamiento carcelario. 
Para hacer frente a esta crisis sanitaria del COVID-19 se requiere la adopción de esfuerzos concentrados en estándares dentro de los cuales se pueden citar: 1. velar para que las autoridades responsables por la detención sean parte de las fuerzas de tarea encargadas de la definición y puesta en marcha de estrategias, planes y protocolos para la prevención y control de la pandemia; 2- velar para que sean elaboradas políticas públicas para fortalecer las capacidades de prevención y respuesta ante la pandemia; 3- velar para que sean definidos protocolos para la prevención del COVID-19 en lugares de detención y la adecuada atención de personas con riesgo de mayores complicaciones que estén presas por medio de políticas públicas elaboradas en coordinación entre el Poder Judiciario y las autoridades carcelarias; 4- asegurar que todos los protocolos producidos tengan una perspectiva llevando en consideración las necesidades de grupos en especial condición de vulnerabilidad, como personas con discapacidad, ancianos, embarazadas, mujeres en fase de lactancia, y madres; 5- desarrollar un protocolo con el respaldo del Ministerio de Salud para la difusión de mensajes educativos dirigidos a todas las personas que ingresan, trabajan y/o vivan en los lugares de detención, lo que incluye personal administrativo y visitas, sobre el virus, sus modos de transmisión, los síntomas de la enfermedad y las medidas a ser aplicadas para evitar el contagio, lo que incluye el lavado frecuente y correcto de manos con abundante agua y jabón, la distancia social de por lo menos 1 metro entre las personas, no tocarse boca, nariz y ojos, y estornudar o toser en el ángulo interno del codo; 6 - garantizar que la información sea brindada por personal capacitado e incluso, que se informe lo que las personas tienen que hacer una vez que aparezcan los síntomas de la enfermedad; 7- asegurar que todas las personas que ingresan trabajan, y/o vivan en los lugares de detención respetan las medidas indicadas en los protocolos incluso cuanto el uso adecuado de mascarillas, desinfectantes, lavado de manos, entre otras.

Estos esfuerzos garantizan los derechos humanos de los presos que como dicho, aun estén presos, son seres humanos y el fato de tener su libertad privada de manera temporaria no les quita el derecho a tener su dignidad respectada.

Además de eso, también es importante garantizar la salud y la seguridad de las personas que vayan a permanecer en prisión dotando los lugares de detención 
como mínimo de los siguientes insumos esenciales: mascarillas, barbijos y tapabocas, termómetros infrarrojos, alcohol en gel, solución de base de alcohol para limpieza, jabón, toallas desechables de papel para el secado de mano, y lo principal: que haya agua para que todos los presos puedan hacer su higiene personal.

Los gobiernos deben establecer un sistema de coordinación actualizado que reúna a los sectores de salud y justicia, mantenga al personal de la prisión bien informado y garantice que todos los derechos humanos en las instalaciones carcelarias sean respetados.

A esta situación traemos las palabras de Zaffaroni (2020), quien considera que la Constitución Política debe aplicarse a modo de marco jurídico durante la imposición de penas, pues de lo contrario se puede incurrir en la imposición de tratos crueles, inhumanos y degradantes, si conociendo la situación carcelaria provocada por el hacinamiento y la carencia de condiciones mínimas de subsistencia, se procede a la imposición de penas privativas de libertad, en tanto se terminaría atentando contra los mismos bienes jurídicos que el Derecho Penal busca proteger.

Se puede concluir así que las medidas adoptadas para combatir la crisis sanitaria del COVID-19 en el sistema carcelario es un proceso de democratización progresista, caracterizado por situar al preso como sujeto de derechos ciudadanos, dando cumplimiento constitucional a derechos inalienables e inherentes, como son los derechos fundamentales de la Carta Magna en constituciones democráticas.

\section{CONCLUSIONES}

Las consecuencias que América del Sur viene enfrentando frente a la situación del COVID-19 corresponden a un modelo punitivo que enfoca sus acciones en el castigo y no apunta a la resocialización. Esto tiene que ver con la política criminal adoptada que ve las cárceles como la única solución a cualquier problema social que se manifieste. Así surgen leyes extremamente punitivas, con incremento de penas, disminución de garantías y de derechos humanos, con una criminalización constante de conductas y que consideran en criminoso un enemigo del Estado y no un ciudadano. Todas estas características se juntan para hacer del sistema 
penitenciario insuficiente, ineficiente y colapsado, donde hay tortura, deshumanización y no se cumplen las funciones de resocialización.

Respecto al panorama penitenciario en Brasil, resulta que la crisis carcelaria no se limita estrictamente al hacinamiento, sino que remonta también a la manera como el Estado trata la cuestión de las personas privadas de libertad, no respetando las mínimas garantías de la dignidad humana, deshumanizando los presos y violando sus derechos humanos.

Es verdad que Brasil ocupa una posición destacada en lo que se refiere a la población carcelaria. Brasil tiene una de las poblaciones carcelarias más grandes del mundo y estos números tienden a aumentar cada vez más, especialmente debido al rigor que el legislador está dando al Derecho Penal, como si el aumento de las sanciones y la creación de nuevos delitos puedan ser soluciones adecuadas para enfrentar el problema de la criminalidad. Si por un lado lo que se busca es poner fin a la cuestión de la criminalidad, por otro, lo que tenemos es una falla técnica legislativa para elegir los instrumentos y herramientas que se utilizarán en este esfuerzo.

En Brasil, entrar en una cárcel significa perder los para una vida digna no solo porque los establecimientos carcelarios en Brasil son lugares donde no son respetadas las mínimas garantías de la dignidad humana sino también porque no hay atención sanitaria a los reclusos, no hay acceso rápido a la atención médica para casos urgentes, los locales de alojamiento de los reclusos no cumplen con normas de higiene y especialmente hay una sobrepoblación que repercute y afecta el acceso de los presos a la salud y a la higiene. Es decir: las cárceles no solo no cumplen su objetivo resocializador sino que además deshumanizan los presos. Se trata de una cuestión grave porque la población carcelaria es vulnerable dadas las condiciones de precarización a las que están sometidos los reclusos.

Por lo tanto, resulta importante un control eficaz de la infección en el medio penitenciario, por medio de una coordinación estrecha entre los sectores de la salud, los servicios sanitarios de los centros penitenciarios y Poder Judiciario para hacer frente a este estado de pandemia que enfrentamos en los días de hoy.

\section{REFERÊNCIAS}


ARGENTINA. [Constituição (1994)]. Constitución de la Nación Argentina. Buenos Aires: Presidencia de la Nación, [1995]. Disponível em:

http://servicios.infoleg.gob.ar/infolegInternet/anexos/0-4999/804/norma.htm Acesso em: 20 set. 2020.

BRASIL. Decreto-lei no 2.848, de 07 de dezembro de 1940. Brasília, DF: Presidência da República, [2019]. Disponível em:

http://www.planalto.gov.br/ccivil_03/decreto-lei/del2848compilado.htm. Acesso em: 10 out. 2020.

BRASIL. Supremo Tribunal Federal. Tutela Provisória Incidental na Arguição de Descumprimento de Preceito Fundamental no 347. Brasília, DF: STF, 2020. Disponível em:

http://www.stf.jus.br/arquivo/cms/noticiaNoticiaStf/anexo/ADPF347decisao.Covid19. pdf. Acesso em: 20 set. 2020.

CONSELHO NACIONAL DE JUSTIÇA (Brasil). Recomendação n ${ }^{\circ} \mathbf{2}$, de 17 de março de 2020. Brasília, DF, 2020b. Disponível em: https://www.cnj.jus.br/wpcontent/uploads/2020/03/62-Recomenda\%C3\%A7\%C3\%A3o.pdf. Acesso em: 18 set. 2020.

CONSELHO NACIONAL DE JUSTIÇA (Brasil). Justiça em números 2020. Brasília, DF: CNJ, 2020a. Disponível em: https://www.cnj.jus.br/wpcontent/uploads/2020/08/WEB-V3-Justi\%C3\%A7a-em-N\%C3\%BAmeros-2020atualizado-em-25-08-2020.pdf. Acesso em: 18 set. 2020.

CONSELHO NACIONAL DE JUSTIÇA (Brasil). Registro de contagios e óbitos. Brasília, DF: CNJ, [2020]. Disponível em: https://www.cnj.jus.br/sistemacarcerario/covid-19/registros-de-contagios-obitos/. Acesso em: 10 out. 2020.

DE LA FUENTE, Javier Esteban. Ejecución de la pena privativa de la libertad: comentário a la ley 24,460 reformada por la ley 27.375. Ciudad Autónoma de Buenos Aires: Editores del Sur, 2019.

DEPARTAMENTO PENITENCIÁRIO NACIONAL (Brasil). Levantamento nacional de informações penitenciárias: dezembro de 2019. [S. l.: s. n.], 2019. Disponível em:

https://app.powerbi.com/view?r=eyJrIjoiZTIkZGJjODQtNmJIMi00OTJhLWFIMDktNzRI NmFkNTMOMWI3IiwidCI6ImViMDkwNDIwLTQONGMtNDNmNy05MWYyLTRiOGRhNm] mZThIMSJ9. Acesso em: 10 out. 2020.

LUCERO, Gerald. Cárceles latinoamericanas, incubadoras para propagar el coronavirus. Connectas, [2020]. Disponível em:

https://www.connectas.org/analisis/carceles-latinoamericanas-incubadoras-parapropagar-coronavirus/. Acesso em: 20 set. 2020.

OMS. Declaración conjunta de la UNODC, la OMS, el ONUSIDA y la ACNUDH sobre la COVID-19 en prisiones y otros centros de detención. [S. I.]: OMS, 
2020. Disponível em: https://www.who.int/es/news/item/13-05-2020-unodc-whounaids-and-ohchr-joint-statement-on-covid-19-in-prisons-and-other-closedsettings\#: : :text=Reducir\%20el\%20hacinamiento\&text=Exhortamos $\% 20 \mathrm{a} \% 2010 \mathrm{~s} \% 2$ 0|\%C3\%ADderes\%20pol\%C3\%ADticos,que\%20se \%20evite\%20la\%20reclusi\%C3\% B3n. Acesso em: 10 out. 2020.

PARDO, Daniel. Coronavirus: "Estamos durmiendo uno encima del otro": cómo el coronavirus está incrementando la tensión en las precarias cárceles de América Latina. BBC News Mundo, Colombia, 5 mayo 2020. Disponível em: https://www.bbc.com/mundo/noticias-america-latina-52538256 Acesso em: 20 set. 2020.

RIVERA BEIRAS, Iñaki. La cuestión carcelaria: historia, epistimología, derecho y política penitenciaria. Ciudad Autónoma de Buenos Aires: Del Puerto, 2009.

WORLD HEALTH ORGANIZATION. Preparedness, prevention and control of COVID-19 in prisons and other places of saluddetention. Copenhagen: WHO, 2020. Disponível em:

https://www.euro.who.int/_data/assets/pdf_file/0019/434026/Preparednessprevention-and-control-of-COVID-19-in-prisons.pdf?ua=1. Acesso em: 10 out. 2020.

ZAFFARONI, Eugenio Raúl. Manual de derecho penal: parte general. Ciudad Autónoma de Buenos Aires: Ediar, 2017.

ZAFFARONI, Eugenio Raúl. Penas ilícitas: un desafío a la dogmática penal. Ciudad Autónoma de Buenos Aires: Editores del Sur, 2020. Recuperado de: http://diazydiazgroup.com/index.php/k2/item/download/127_45053b2a5fb1f8140e92 3d6f6858faa5

ZYSMAN QUIRÓS, Diego. Sociologia del castigo: genealogia de la determinación de la pena. Buenos Aires: Ediciones Didot, 2012. 